Document downloaded from:

http://hdl.handle.net/10251/103791

This paper must be cited as:

Payri, R.; Bracho Leon, G.; Marti-Aldaravi, P.; Viera-Sotillo, AA. (2017). Near field visualization of diesel spray for different nozzle inclination angles in non-vaporizing conditions. Atomization and Sprays. 27(3):251-267. doi:10.1615/AtomizSpr.2017017949

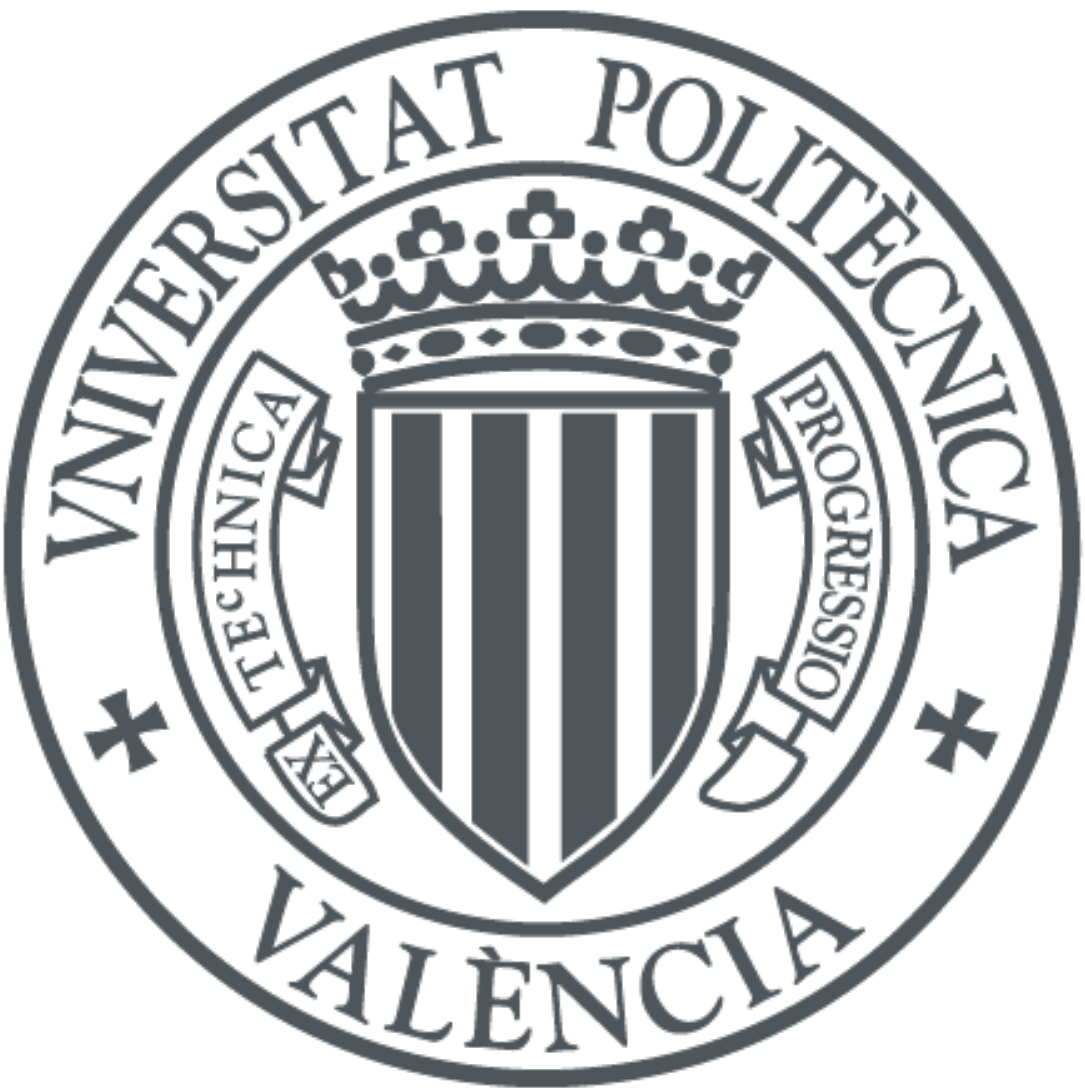

The final publication is available at

http://doi.org/10.1615/AtomizSpr.2017017949

Copyright Begell House Inc.

Additional Information 
Raúl Payri, Gabriela Bracho, Pedro Martí-Aldaraví, Alberto Viera; Near field visualization of diesel spray for different nozzle inclination angles in non-vaporizing conditions. Atomization and Sprays, 2017, 27(3), 251-267.

\title{
Near field visualization of diesel spray for different nozzle inclination angles in non-vaporizing conditions
}

\author{
Raúl Payri*, Gabriela Bracho, Pedro Martí-Aldaraví, Alberto Viera \\ CMT - Motores Térmicos, Universitat Politècnica de València, Edificio 6D, 46022, Valencia, Spain.
}

\begin{abstract}
Accurate experimental data is often needed to validate computational fluid dynamics models. These models regularly rely on experimental results from single orifice axially drilled nozzles that do not fully represent real injectors, as the difference in inclination angles create turbulent conditions at the nozzle outlet which consequences on the spray development are not yet fully understood. In this work, near field visualization was done for two nozzle inclination angles in non-vaporizing conditions. Spray tip penetration, spreading angle, and axis angle fluctuations are reported. Three hypotheses are analyzed: liquid jet breakup mechanism, internal flow development, and cavitation. Experiments were carried out using n-Dodecane, testing a single orifice axially drilled and a three orifice injector, from the Engine Combustion Network. The spray was observed with a diffused back-illumination technique and a long distance microscope, only visualizing the first $6 \mathrm{~mm}$ of spray tip penetration, for three injection pressures and four gas densities at ambient temperature. The multi orifice injector produced a spray with wider spreading angle, which resulted in smaller penetration values. Additionally, higher spray axis angle fluctuations were observed for the multi orifice injector, which increased for higher injection pressure and, to a lesser extent, with decreasing chamber density. Further analysis was performed with spreading angle fluctuations measurements, where results showed good agreement with spray axis angle fluctuations trends, implying that complex internal flow structures, and even incipient cavitation, could be present in the multi orifice injector and be the cause of these spray axis angle fluctuations.
\end{abstract}

Keywords: Diesel injection, liquid phase penetration, spray axis angle fluctuation, DBI

\section{Introduction}

Diesel spray formation and mixing have been determined as key factors in combustion control and reduction of its related contaminants. Both experimental and computational results have proven that the

${ }^{*}$ Corresponding author. E-mail address: rpayri@mot.upv.es . 
Raúl Payri, Gabriela Bracho, Pedro Martí-Aldaraví, Alberto Viera; Near field visualization of diesel spray for different nozzle inclination angles in non-vaporizing conditions. Atomization and Sprays, 2017, 27(3), 251-267.

\begin{tabular}{|llll|}
\hline \multicolumn{2}{l}{ Nomenclature } & & \\
$\alpha$ & Spray axis angle & & \\
$\dot{m}$ & Mass flow rate & $P_{b}$ & Back pressure \\
$\dot{m}_{t h}$ & Theoretical mass flow rate & $P_{i n j}$ & Injection pressure \\
$\mu_{f}$ & Fuel dynamic viscosity & $T$ & Temperature \\
$\bar{\alpha}$ & Averaged spray axis angle fluctuation & $u_{o}$ & Injection velocity \\
$\bar{\theta}$ & Averaged spreading angle fluctuation & CFD & Computational fluid dynamics \\
$\rho$ & Ambient density & Do & Orifice outlet diameter \\
$\rho_{f}$ & Fuel density & LES & Large eddy simulation \\
$\sigma$ & Surface tension & Nrep & Total number of repetitions \\
$\theta$ & Spray spreading angle & ROI & Rate of injection \\
$C_{d}$ & Discharge coefficient & s & Spray tip penetration \\
$k$-factor & Nozzle orifice conicity factor & SOE & Start of energizing \\
& & SOI & Start of injection \\
\hline
\end{tabular}

nozzle geometry has a fundamental influence on the internal flow development, and macroscopic behavior 5 of the spray (Arcoumanis et al., 1998, Payri et al., 2004b, 2015, Sou and Pratama, 2016). Siebers and Higgins (2001) proved that mixing is mainly controlled by turbulence. Consequently, recent trends in diesel technology have shown that increasing injection pressure and reducing the diameter of the nozzle result in an improvement of the spray mixing and benefit the overall combustion development (Pierpont and Reitz, 1995, Bergstrand and Denbratt, 2001). Computational Fluid Dynamics (CFD) is used to improve the understanding of the process, and obtain parameters which can be difficult to measure experimentally, but often rely on accurate experimental data in order to be validated. The current trend in diesel simulation is to do seamless calculations of internal and external flow using Large Eddy Simulation (LES) (Battistoni et al. 2016), which allows no domain interpolation of results between coupled simulations. An advantage of these models is that they simulate large scale turbulence phenomena, enabling them to reproduce local effects of complex internal flow structures, but as the level of detail gets higher, a more detailed and reliable experimental data is necessary to validate these models.

The Engine Combustion Network (ECN) is an international collaboration group that unites efforts from different institutions around the world to improve the scientific understanding of the spray combustion at engine relevant conditions, by establishing a library of reliable experimental data appropriate for model validation $(\mathrm{ECN}, 2010)$. The ECN uses single and multi-hole injectors with nominally identical specifications (Kastengren et al. 2012), which allows comparing the effect of different nozzle geometries on the spray 
Raúl Payri, Gabriela Bracho, Pedro Martí-Aldaraví, Alberto Viera; Near field visualization of diesel spray for different nozzle inclination angles in non-vaporizing conditions. Atomization and Sprays, 2017, 27(3), 251-267.

development. Moreover, the multi-hole injector is a three orifice nozzle where the holes are not equally spaced, and consequently, one hole is isolated from the others. For this reason, it is possible to perform line of sight visualization additional to the regular multi-hole spray studies, calculating different variables and relating them to the same injection event.

The present work is focused on the near field visualization of the diesel spray produced by two ECN nozzles with different inclination angles in non-vaporizing conditions. Three macroscopic spray variables are measured for an injection event: tip penetration, spreading angle and spray axis fluctuations. Tip penetration is defined as the distance between nozzle exit and the furthest spray contour detected in the whole domain. Regarding the spray spreading angle, there are several possible definitions in the literature, but the proposed method is presented in section 2.4. Spray axis angle was calculated with the definition used by Mendez et al. (2013), defined as the angle between the axis of the injector and the calculated centroid of the spray contour (with the nozzle orifice as reference). The axis of the injector is calculated as a time averaged spray axis. These calculations are done for the whole injection event and for each repetition.

Figure 1 presents a scheme of the definitions.

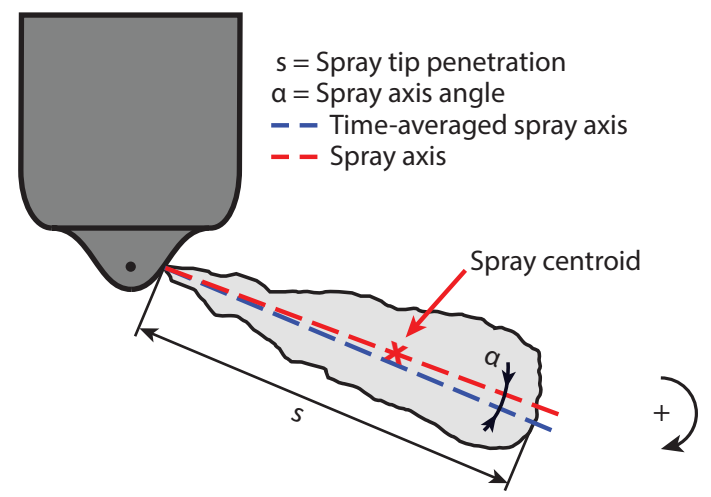

Figure 1: Definitions of traced spray variables for a time instant. Tip penetration is defined as the distance between exit orifice and the furthest pixel of the spray detected. The axis angle fluctuation described as the angle between the calculated centroid of the contour of the spray, and the time-averaged spray axis.

From this definition, it is important to remark that spray axis angle fluctuations occur when the centroid of the spray is not aligned with the averaged spray axis. This can happen in two conditions:

- Whole spray oscillations around the averaged spray axis.

- Asymmetric changes in the spreading angle. If one edge of the spray changes while the symmetric portion on the opposite edge remains at the same position, the centroid of the spray is displaced. 
Raúl Payri, Gabriela Bracho, Pedro Martí-Aldaraví, Alberto Viera; Near field visualization of diesel spray for different nozzle inclination angles in non-vaporizing conditions. Atomization and Sprays, 2017, 27(3), 251-267.

Little information is known about the occurrence of the fluctuations and its consequences on the penetration of the spray. Jung et al. (2015) studied the effect of spreading angle variations through an injection event on liquid and vapor penetration, but spray axis fluctuations are not taken into account. On the other hand, Mendez et al. (2013) induced a spray axis angle by the means of electric fields, that produced a constant deviation from the spray natural axis angle, and concluded that it did not affect spray penetration, but spray axis fluctuations produced by boundary conditions were not studied.

In this study, three different hypotheses are considered as a possible cause for this phenomenon: liquid jet breakup mechanism, complex internal flow structures, and cavitation.

Reitz and Bracco (1984) distinguished four different mechanisms for jet breakup: Rayleigh, first and second wind-induced breakup and full atomization. Typical diesel injection conditions create fully atomized sprays. But if full atomization is not achieve for specific conditions, the intact surface length of the spray is not zero, and non-uniform liquid wave breakup could result in higher spray axis angle fluctuations. By calculating the Reynolds and Ohnesorge numbers ( $R e$ and $O h$ in Equations 1 and 2 respectively), and using the Ohnesorge diagram limits presented by Reitz and Bracco (1984), it is possible to obtain the jet breakup mechanism for certain boundary conditions.

$$
\begin{gathered}
R e=\frac{u_{o} D_{o} \rho_{f}}{\mu_{f}} \\
O h=\frac{\mu_{f}}{\sqrt{\rho_{f} \sigma D_{o}}}
\end{gathered}
$$

Where $u_{o}$ is the injection velocity at the exit of the nozzle, $D_{o}$ orifice outlet diameter, $\rho_{f}$ density of the fluid, $\mu_{f}$ fuel dynamic viscosity, and $\sigma$ is its surface tension.

Another reason behind spray axis angle fluctuations could be the presence of relevant radial velocity components. When fuel is traveling through the nozzle, it has both an axial component in velocity, due to the flow direction, and a radial component due to the turbulence and nozzle geometry (Arcoumanis et al. 1998). In single orifice axially drilled injectors, commonly used for research, the nozzle is aligned with the axis of the injector, meaning that flow enters uniformly into the nozzle, and radial components of velocity are only related to nozzle convergence. On the contrary, for multi orifice injectors, flow needs to change direction because the axis of the nozzle is not aligned with the injector, this increases turbulence in the flow, as radial velocity components of higher magnitude are expected (Arcoumanis et al., 1998). For nozzles with same conicity factor (or $k$-factor), the difference in inclination angles could lead to multi orifice nozzle 
Raúl Payri, Gabriela Bracho, Pedro Martí-Aldaraví, Alberto Viera; Near field visualization of diesel spray for different nozzle inclination angles in non-vaporizing conditions. Atomization and Sprays, 2017, 27(3), 251-267.

having bigger spray axis angle fluctuations than single axially drilled injectors.

A third reason behind the fluctuations of the spray axis angle could be cavitating conditions at the nozzle. Because flow is being strangulated through a very small orifice with high velocity, it creates local conditions that tend to ease the apparition of high turbulence or even cavitation. Payri et al. (2015) observed two different nozzles, one cavitating and one non-cavitating, concluding that cavitation induced higher spreading angle fluctuations. Desantes et al. (2010), tested a nozzle in both cavitating and noncavitating conditions, observing oscillations in the spray boundaries for the cavitating case. Both cases described before could be translated into spray axis angle fluctuations following the definition from Figure 1. Nurick (1976) proposed that the inception of cavitation relates to a point where mass flow collapses, this allowed a non intrusive way to determine cavitating conditions for injectors, by measuring mass flow for different injection and chamber pressures. Nonetheless, other authors (Winklhofer et al. 2001; Mishra and Peles, 2005), proved that cavitation starts before mass flow collapses, but it is only reflected in the mass flow when there is a considerable amount of bubbles to affect the pressure field in the nozzle. Although this was also experimentally visualized by other authors (Desantes et al., 2010, Payri et al., 2005), still remains as a good experimental indicator that at those conditions cavitation is present.

This paper is divided into four sections. Following this introduction, the injection system and experimental facilities are described, along with details of the optical setup and experimental methodology used in this work. Results related to the macroscopic spray parameters are presented and discussed next, followed by the corresponding analysis of each hypothesis for the spray axis angle fluctuations. The last section presents the conclusions.

\section{Materials and Methods}

This section presents the experimental installation and the methodologies used.

\subsection{Injection system}

The injection system is formed by commercially available components. High pressure is achieved and sustained by a volumetric Bosch CP3 pump driven by an electric motor, and a common rail with a pressure regulator controlled through a PID system. The injector is connected to the common rail with a high pressure line, and inserted into the vessel through a holder that has a continuous flow of ethylene glycol running in a temperature controlled circuit, set to keep nozzle tip temperature constant (Payri et al., 2012$)$. 
Raúl Payri, Gabriela Bracho, Pedro Martí-Aldaraví, Alberto Viera; Near field visualization of diesel spray for different nozzle inclination angles in non-vaporizing conditions. Atomization and Sprays, 2017, 27(3), 251-267.

The common rail, high pressure line and sensor setup was assembled following the ECN standards ECN, 2010).

Both single and multi orifice injectors with nominally identical specifications were used. For the axially drilled single orifice injector, the relative angle between the nozzle and its axis is zero, on the contrary, for the multi orifice injector, this angle has a nominal value of $72.5^{\circ}$ ( $145^{\circ}$ full angle included). The nozzles are referred to as Spray A and Spray B respectively. As they are part of the ECN dataset (ref: \#0210675 and \#0211200), the internal geometry of both injectors have been thoroughly studied and can be found on the ECN web page (ECN, 2010). A brief summary of some characteristics of each injector is presented in Table 1. A single component fuel (n-Dodecane) was used, following ECN guidelines.

Table 1: Nozzle specifications $(\mathrm{ECN}, 2010)$.

\begin{tabular}{lll}
\hline Parameter & Spray A & Spray B \\
\hline Reference number & 0210675 & 0211200 \\
Number of orifices & 1 & $3^{*}$ \\
Orifice diameter $\left(\mathrm{D}_{o}\right)$ & $89.4 \mu \mathrm{m}$ & $93.2^{*} \mu \mathrm{m}$ \\
Nominal $k$-factor & 1.5 & 1.5 \\
Relative angle & $0^{\circ}$ & $72.5^{\circ}$ \\
\hline${ }^{*}$ Orifice of interest is $180^{\circ}$ from the fuel inlet port. \\
+ Between the axis of the nozzle and the injector.
\end{tabular}

\subsection{Rate of injection measurements}

With the hydraulic characterization of an injector, it is possible to estimate the liquid jet breakup mechanism (Reitz and Bracco, 1984) and observe if mass flow collapses for certain conditions (Desantes et al. 2010). Rate of injection (ROI) was measured in a standard injection rate discharge curve indicator, based on the Bosch method and explained by Payri et al. (2008a). Because Spray A has been thoroughly investigated and characterized, both experimentally and through CFD modeling, rate of injection was measured only for Spray B. Mass flow choking can be observed by plotting mass flow to the square root of the pressure difference, or by observing the behavior of discharge coefficient $\left(C_{d}\right)$ to $R e$ (Payri et al., 2004a, 2005). Discharge coefficient can be calculated with the following equation:

$$
C_{d}=\frac{\dot{m}}{\dot{m}_{t h}}=\frac{\dot{m}}{A_{0} \sqrt{2 \rho_{f}\left(P_{i n j}-P_{b}\right)}}
$$

Where $\dot{m}$ and $\dot{m}_{t h}$ are the real and theoretical mass flow respectively, $P_{i n j}$ is the injection pressure and $P_{b}$ is the back pressure. Real mass flow is estimated from the ROI measurements, where the temperature 
Raúl Payri, Gabriela Bracho, Pedro Martí-Aldaraví, Alberto Viera; Near field visualization of diesel spray for different nozzle inclination angles in non-vaporizing conditions. Atomization and Sprays, 2017, 27(3), 251-267.

is also traced to calculate fuel density and viscosity (Bell et al., 2014). For each condition, it is possible to obtain the Ohnesorge number with Equation 2, where surface tension is also obtained for the measured fuel temperature.

To fully understand the hydraulic behavior of the injector and cover all possible conditions for determining the liquid breakup mechanism, a detailed parametric sweep of injection and back pressure was performed. Conditions tested are presented in Table 2

Table 2: ROI measurement conditions for Spray B nozzle.

\begin{tabular}{lll}
\hline Parameter & Values & Units \\
\hline Fuel & n-Dodecane & - \\
\hline Energizing time & 2.5 & $\mathrm{~ms}$ \\
\hline Nozzle tip temperature & 343 & $\mathrm{~K}$ \\
\hline Back pressure $\left(P_{b}\right)$ & $0.5-1-1.5-2-4-6-8$ & $\mathrm{MPa}$ \\
\hline Injection pressure $\left(P_{i n j}\right)$ & $30-50-75-100-125-150-175-200$ & $\mathrm{MPa}$ \\
\hline
\end{tabular}

\subsection{Spray chamber}

An optically accessible constant pressure and flow vessel was used, where nitrogen is fed directly from a pressurized reservoir. A closed loop PID system regulates the back pressure, and although the temperature is not controlled, it is monitored constantly and back pressure is adjusted to achieve constant density, with an error lower than $2 \%$. Due to the nature of this vessel, only low temperature (around ambient values) are achieved. On the contrary, as there is no need to heat the gas before it enters the chamber as other vessels (Payri et al. 2016b), numerous variations in boundary conditions can be performed without a time penalty.

\subsection{Diffused back-illumination}

Liquid phase penetration is often used in the literature to characterize the mixing process in diesel sprays (Siebers, 1998, Payri et al. 2012, 2016a, Hulkkonen et al., 2015). There are multiple optical methodologies to visualize the liquid phase penetration and development (Bardi et al., 2012). As seen in Figure2, a diffused back-illumination (DBI) setup was used to visualize the spray in the line of sight. Light from a source is passed through a diffuser, creating a diffusely illuminated surface, which is reproduced and amplified in the spray plane by a field lens. The liquid spray blocks the light and prevents it from entering the camera. As a consequence, the liquid part of the spray is seen as dark pixels in the image. This technique has been widely used in spray visualization, but the recent implementation of a light-emitting diode (LED) has improved 
Raúl Payri, Gabriela Bracho, Pedro Martí-Aldaraví, Alberto Viera; Near field visualization of diesel spray for different nozzle inclination angles in non-vaporizing conditions. Atomization and Sprays, 2017, 27(3), 251-267.

the quality because image stillness is limited by the pulse length of the LED and not the exposure of the camera, producing images significantly sharper than any other continuous light source options (Payri et al. 2015, Manin et al., 2012).

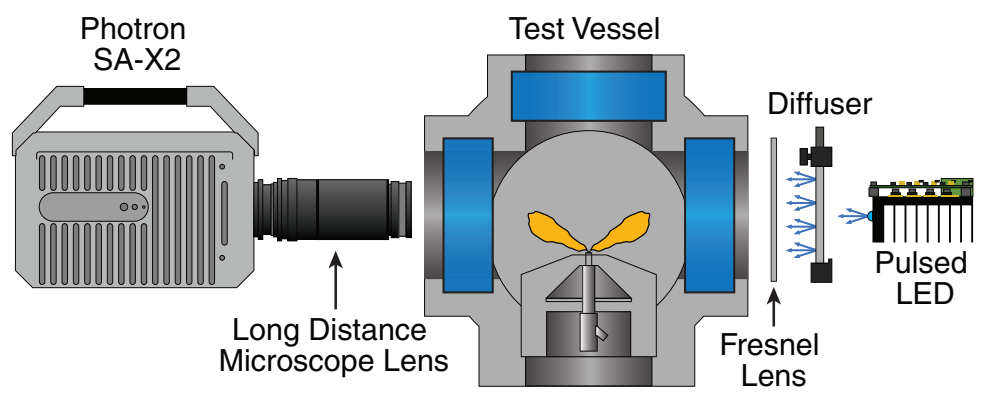

Figure 2: Schematic of the setup used. Diffused back-illumination is performed with a pulse LED, diffuser and a field lens. High pixel-mm was obtained using a long distance microscopic lens.

Data from the DBI setup was processed following the methodology explained by Payri et al. (2015), with a purpose developed software. After inverting the images, the background is obtained by averaging the first frames before the start of injection (SOI), and then subtracted to the each frame after SOI. Images are binarized with a threshold, that is predefined and adjusted just above background noise. The spray contour is defined as the boundary between the white (spray) and black region (chamber and nozzle tip). An example of the spray contour obtained with this processing methodology is presented in Figure 3. Because the DBI spray visualization was done near field at low temperature, problems with beam steering or Schlieren interfering with the setup were avoided, meaning that minor variations in threshold did not affect the contour detection results. Spray tip penetration and spray axis angle results were obtained following the definition explained in section 1. In order to have a comparable value between boundary conditions, the spray axis angle fluctuation $(\bar{\alpha})$ is calculated as the mean standard deviation of the spray axis angle per repetition for a time window, that was kept constant and chosen for stabilized rate of injection intervals. The definition is presented in Equation 4 Note that the final result represents a magnitude of these fluctuations, and it was multiplied by a factor of two to have peak-to-peak results.

$$
\bar{\alpha}=2 \operatorname{Mean}\left(\operatorname{Std}\left(\alpha_{\Delta t_{i}}\right)\right) ; \text { for } i=1: N r e p
$$

Where $\alpha_{\Delta t}$ is the spray axis angle measured for the predetermined time window, and Nrep is the total number of repetitions in the test. Spreading angle is defined as the angle between two linear fits calculated, for a top and bottom profile of the spray, at intervals of 1 and $5 \mathrm{~mm}$ of the spray tip penetration. A scheme of 
Raúl Payri, Gabriela Bracho, Pedro Martí-Aldaraví, Alberto Viera; Near field visualization of diesel spray for different nozzle inclination angles in non-vaporizing conditions. Atomization and Sprays, 2017, 27(3), 251-267.

this definition is presented in Figure 3 , note that due to the field of view, fits are not forced to pass through the origin of the nozzle. As fluctuations in the spreading are also studied, the same strategy presented in Equation 4 was used to obtain the spreading angle fluctuation $(\bar{\theta})$.

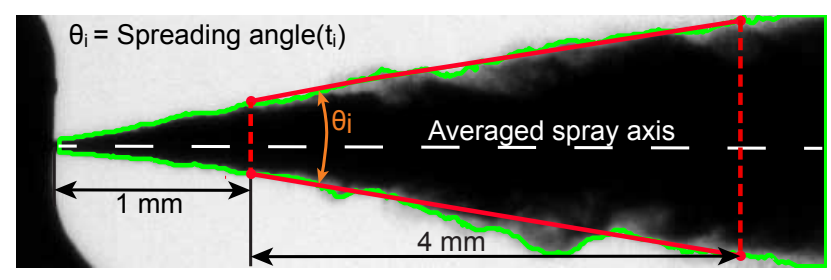

Figure 3: Schematic representation of the spreading angle processing method. The spray is divided into a top and bottom profile through the averaged spray axis. Spreading angle is measured between linear fits calculated at intervals of 1 and $5 \mathrm{~mm}$ of the tip penetration.

\subsection{Detailed optical setup}

Details about the optical setup are presented in Table 3. Pulse length for the LED had to be increased compared to setups by other authors (Payri et al., 2015, Manin et al., 2012), as a consequence of the light lost due to the implementation of a long distance microscope lens. Yet still, the duration of the pulse is significantly smaller than typical camera exposure values used in other experimental setups (e.g. Mie scattering (Bardi et al., 2012)).

Table 3: Detailed optical setup.

\begin{tabular}{lll}
\hline Parameter & & units \\
\hline Camera & Photron SA-X2 & - \\
\hline Lens & Infinity K2 DistaMax & - \\
\hline Frame rate & 120 & kfps \\
\hline Exposure & 3.75 & $\mu \mathrm{s}$ \\
\hline Light Source & Pulsed LED & - \\
\hline Pulse length & 125 & $\mathrm{~ns}$ \\
\hline Repetitions & 8 & - \\
\hline Pixel-mm & 73 & $\mathrm{px} / \mathrm{mm}$ \\
\hline
\end{tabular}

\subsection{Test conditions}

Experimental conditions are summarized in Table 4 It includes Spray A target condition for injection pressure and gas density $\left(P_{i n j}=150 \mathrm{MPa}, \rho=22.8 \mathrm{~kg} / \mathrm{m}^{3}\right)$ as well as parametric variations following the ECN recommendations (ECN, 2010). As mentioned before, chamber temperature was measured for each 
Raúl Payri, Gabriela Bracho, Pedro Martí-Aldaraví, Alberto Viera; Near field visualization of diesel spray for different nozzle inclination angles in non-vaporizing conditions. Atomization and Sprays, 2017, 27(3), 251-267.

test point and back pressure was adjusted to achieve the target density. Energizing time was increased for Spray B because higher fluctuations were observed, this allowed to visualize a stabilized spray for a longer period of time. Additionally, to observe the effect of fuel viscosity in spray axis angle fluctuations, the ethylene glycol temperature was varied also for Spray B.

Table 4: DBI test conditions.

\begin{tabular}{lll}
\hline Parameter & Values & Units \\
\hline Fuel & n-Dodecane & - \\
\hline Energizing time & $2.5-3.5^{*}$ & $\mathrm{~ms}$ \\
\hline Gas density $(\rho)$ & $7.6-15.2-22.8$ & $\mathrm{~kg} / \mathrm{m}^{3}$ \\
\hline Back pressure $^{x}\left(P_{b}\right)$ & $\approx 0.67-1.33-1.99-2.65$ & $\mathrm{MPa}$ \\
\hline Gas temperature $(T)$ & $\approx 295$ & $\mathrm{~K}$ \\
\hline Injection pressure $\left(P_{i n j}\right)$ & $50-100-150$ & $\mathrm{MPa}$ \\
\hline Nozzle tip temperature & $303^{*}-323^{*}-343$ & $\mathrm{~K}$ \\
\hline * Only for Spray B. & & \\
$x$ Correspond to each density in same order. &
\end{tabular}

\section{Results and discussion}

Starting this section, spray tip penetration and spreading angle results between nozzles are presented and discussed, followed by the spray axis angle fluctuations results. To further analyze these fluctuations, results related to the three hypotheses reviewed in this research are presented: the rate of injection measurements (collapse of the mass flow and liquid jet breakup mechanism) and spreading angle fluctuations. Completing the section, additional results on spray axis angle fluctuations are presented.

\subsection{Raw data}

Following the methodology briefly explained in section 2.4, the gathered images were processed to obtain the spray contours. An example of the results obtained is presented in Figure 4.

The figure presents some frames of the experimental movies with the scale and time after start of energizing (SOE) stamped. The top group is for the Spray A nozzle, being the bottom group for Spray B. Each column represents a different injection pressure. Note that for Spray B, the time after SOE for the 4 images selected at each injection pressure is different, but the time steps are equal for all the data presented. Although the frames are only for one repetition, the processing methodology detected the contour of the spray effectively. Furthermore, the high acquisition rate and the sharp image obtained through the 
Raúl Payri, Gabriela Bracho, Pedro Martí-Aldaraví, Alberto Viera; Near field visualization of diesel spray for different nozzle inclination angles in non-vaporizing conditions. Atomization and Sprays, 2017, 27(3), 251-267.

Pinj $50 \mathrm{MPa}$
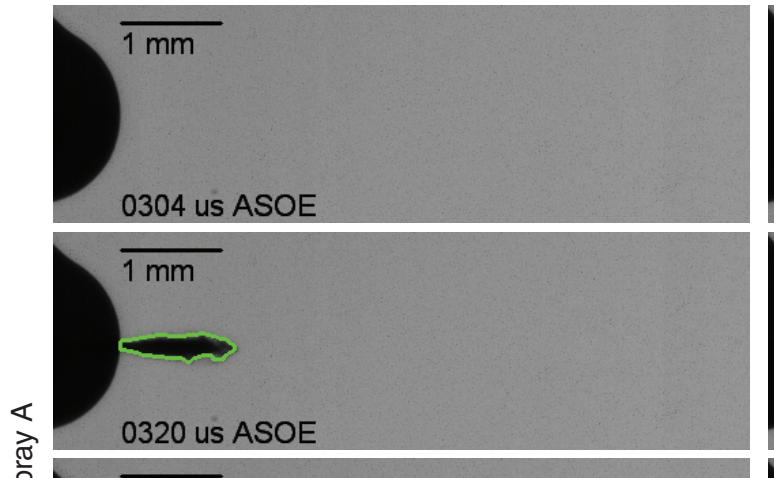

के
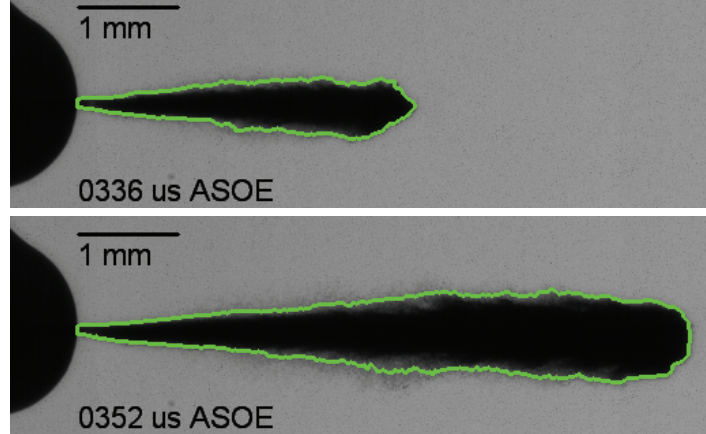

0352 us ASOE
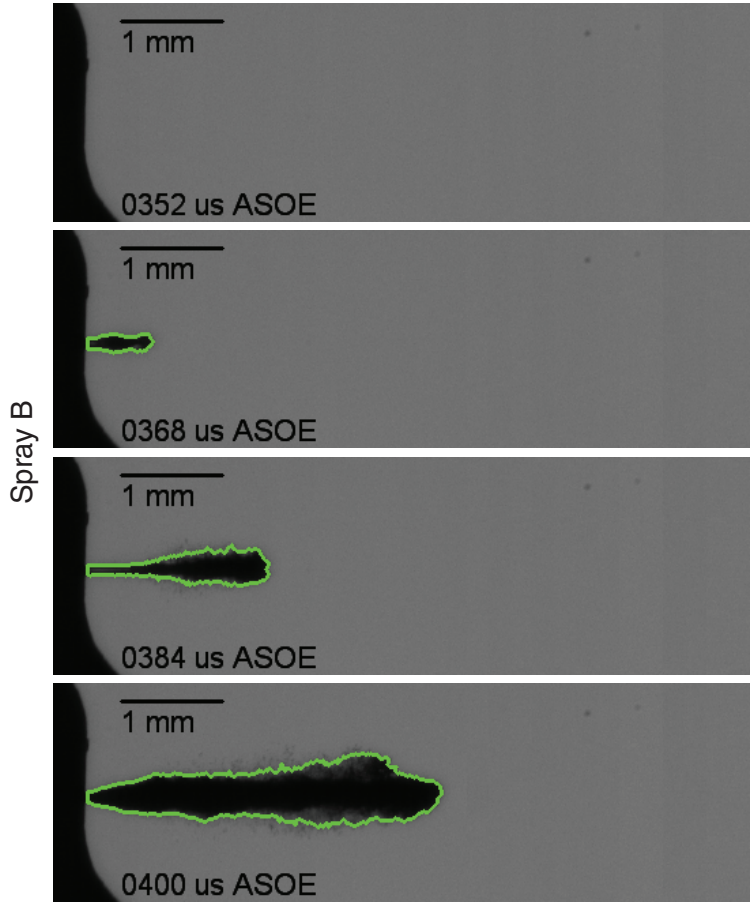

Pinj $150 \mathrm{MPa}$

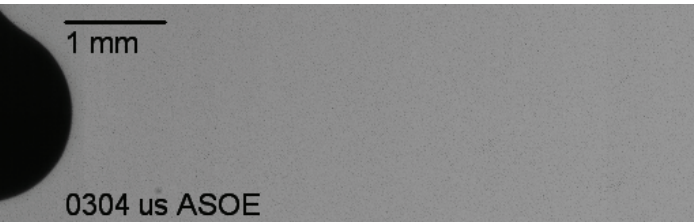

0304 us ASOE

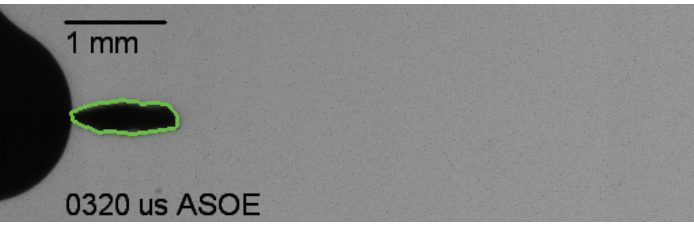

0320 us ASOE

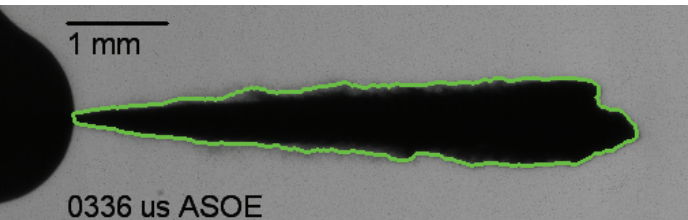

0336 us ASOE

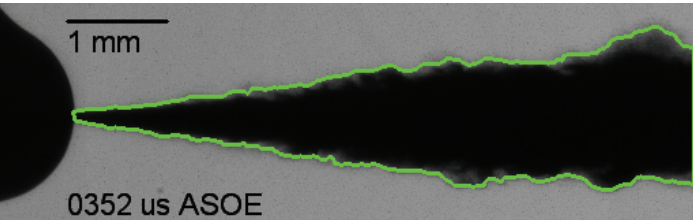

0352 us ASOE
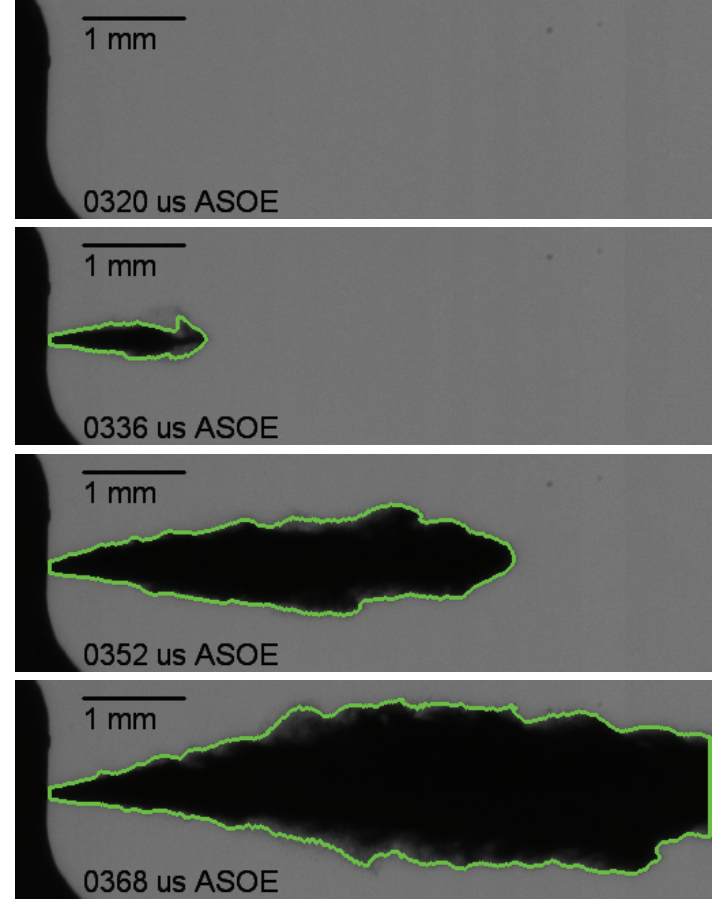

Figure 4: Example of the experimental images with the calculated contour, four time steps are presented for a single repetition. Frames in the top group are for Spray A nozzle, while bottom group are for Spray B. Each column represents a different injection pressure. Note that for Spray B, as opposed to Spray A, the time for each frame is different. 
Raúl Payri, Gabriela Bracho, Pedro Martí-Aldaraví, Alberto Viera; Near field visualization of diesel spray for different nozzle inclination angles in non-vaporizing conditions. Atomization and Sprays, 2017, 27(3), 251-267.

pulsed LED, allowed to detect the spray contour at very early stages in the injection event, resulting in tip penetration values as low as $0.2 \mathrm{~mm}$. Consequently, good estimations of the start of injection were achieved.

\subsection{Spray tip penetration}

Diesel spray tip penetration is one of the most common macroscopic characteristics of study in diesel sprays. Due to the fast acquisition rate, it was possible to visualize the acceleration of the tip penetration during the opening phase of the needle (Manin et al. 2016). Thus, the start of injection was calculated by extrapolating penetrations tip penetration values to zero with a quadratic fit. Spray penetration results are presented in Figure 5 for both nozzles. Data represent an average of all repetitions, estimated following the rolling-average procedure explained by Payri et al. $(2013)$, with a time window of 58 us. The top plot presents the effect of different injection pressures levels at a constant density. On the contrary, bottom plot presents different chamber densities at a given injection pressure. Note that in both cases, conditions tested are represented with symbols. As results show, multi hole nozzle (Spray B) has a slower tip penetration than

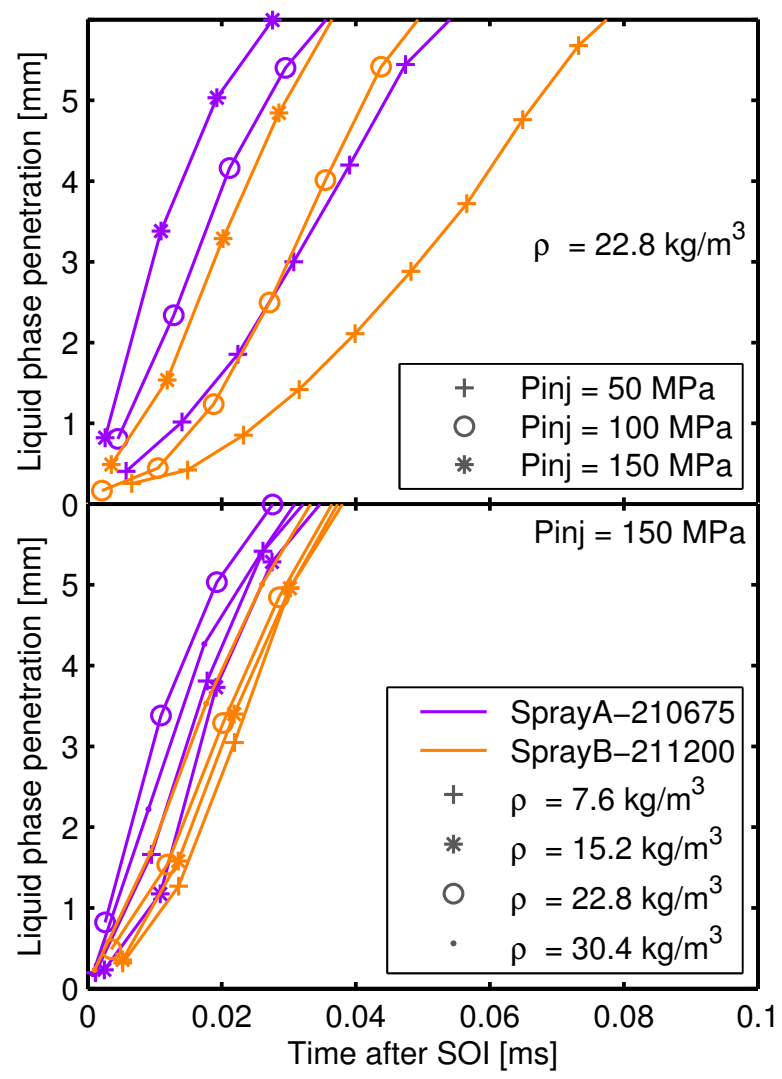

Figure 5: Spray tip penetration versus time. Multi-orifice nozzle (Spray B in orange) shows slower penetration compared to the axially drilled single orifice nozzle (Spray A in purple). For both plots, symbols correspond to different conditions tested. 
Raúl Payri, Gabriela Bracho, Pedro Martí-Aldaraví, Alberto Viera; Near field visualization of diesel spray for different nozzle inclination angles in non-vaporizing conditions. Atomization and Sprays, 2017, 27(3), 251-267.

the single axially drilled nozzle (Spray A), in accordance with results reported in the ECN $(\overline{E C N}, 2010)$. As both nozzles have nominally identical specifications, discrepancies in tip penetration results are related to the momentum flux differences between nozzles that could be caused by a lower sac pressure, or complexities in the internal flow development for the multi hole nozzle. Additionally, thanks to the field of view and high acquisition rate, it is possible to observe the parabolic shape of the tip penetration curve (Manin et al. 2016), as fuel is accelerating due to the needle still being in the opening phase. This is especially noted at lower injection pressure conditions, where the needle lift movement occurs slower. Another expected but notable result from Figure 5 , is that near the nozzle, momentum exchange between fuel and ambient gas has a stronger influence on spray tip penetration than air entrainment (Pastor et al., 2008), as injection pressure variations proved to have a bigger impact on spray tip penetration than density for the range of conditions studied.

\subsection{Spreading angle}

Another common characteristic that helps to describe the macroscopic behavior of a diesel spray is the spreading angle. For the methodology proposed in Figure 3 results were time averaged with the same stabilized rate of injections window chosen for Equation 4 , these are presented in Figure6. Overall conditions tested, and in accordance with tip penetration results of Figure 5. Spray B presents a higher spreading angle than Spray A. Additionally, for near field angle measurements, the two nozzle configurations showed very different trends for density variations. In the axially drilled Spray A, the flow enters the nozzle in an orderly symmetric fashion. On the contrary, for Spray B, due to the change in flow direction within the nozzle, a

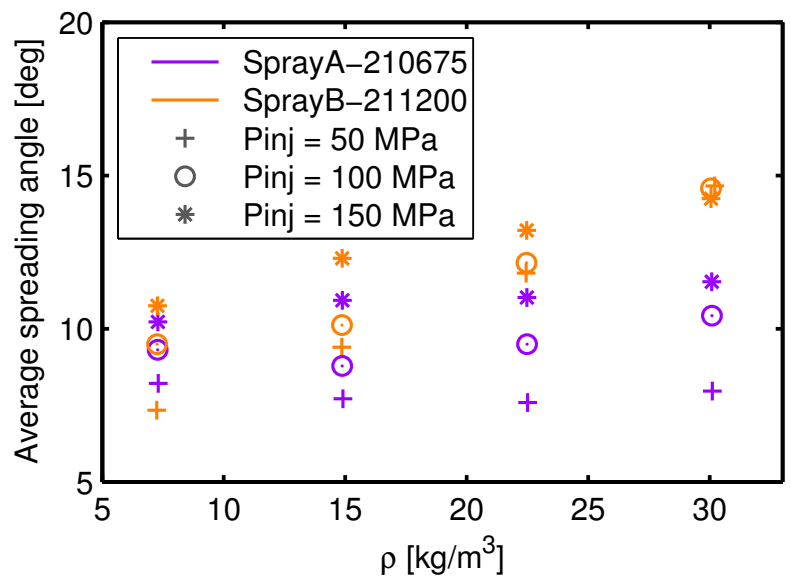

Figure 6: Averaged spreading angle versus density. In general, Spray B presents higher spreading angle than Spray A, in accordance to spray tip penetration results shown in Figure 5 
Raúl Payri, Gabriela Bracho, Pedro Martí-Aldaraví, Alberto Viera; Near field visualization of diesel spray for different nozzle inclination angles in non-vaporizing conditions. Atomization and Sprays, 2017, 27(3), 251-267. complex internal flow structures and cavitation.

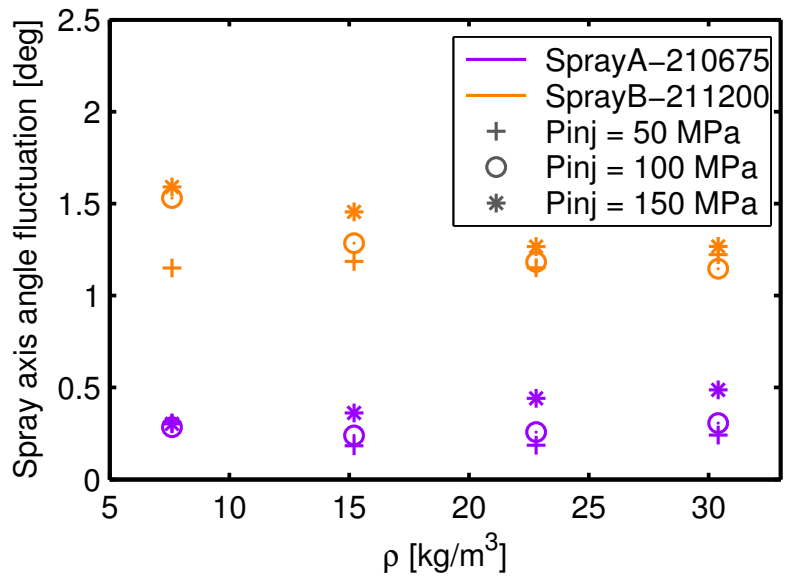

Figure 7: Spray axis angle fluctuations $(\bar{\alpha})$ between nozzles plotted against chamber density. Multi-orifice nozzle (Spray B in orange) shows higher fluctuations compared to the axially drilled single orifice nozzle (Spray A in purple). 
Raúl Payri, Gabriela Bracho, Pedro Martí-Aldaraví, Alberto Viera; Near field visualization of diesel spray for different nozzle inclination angles in non-vaporizing conditions. Atomization and Sprays, 2017, 27(3), 251-267.

\subsection{Averaged mass flow and discharge coefficient}

Mass flow and discharge coefficient results for Spray B are shown in Figure 8, in order to determine if mass flow remains constant under a set of boundary conditions. A very detailed sweep of injection and back pressures was carried out, as previously presented in Table 2 The top plot presents the averaged mass flow in stabilized conditions (grams per second) versus the square root of the pressure difference. The bottom plot shows the discharge coefficient versus the Reynolds number calculated with Equation 1. Note that the injection pressure is presented as a color gradient, although the highlight of these results is the overall trend of the data.
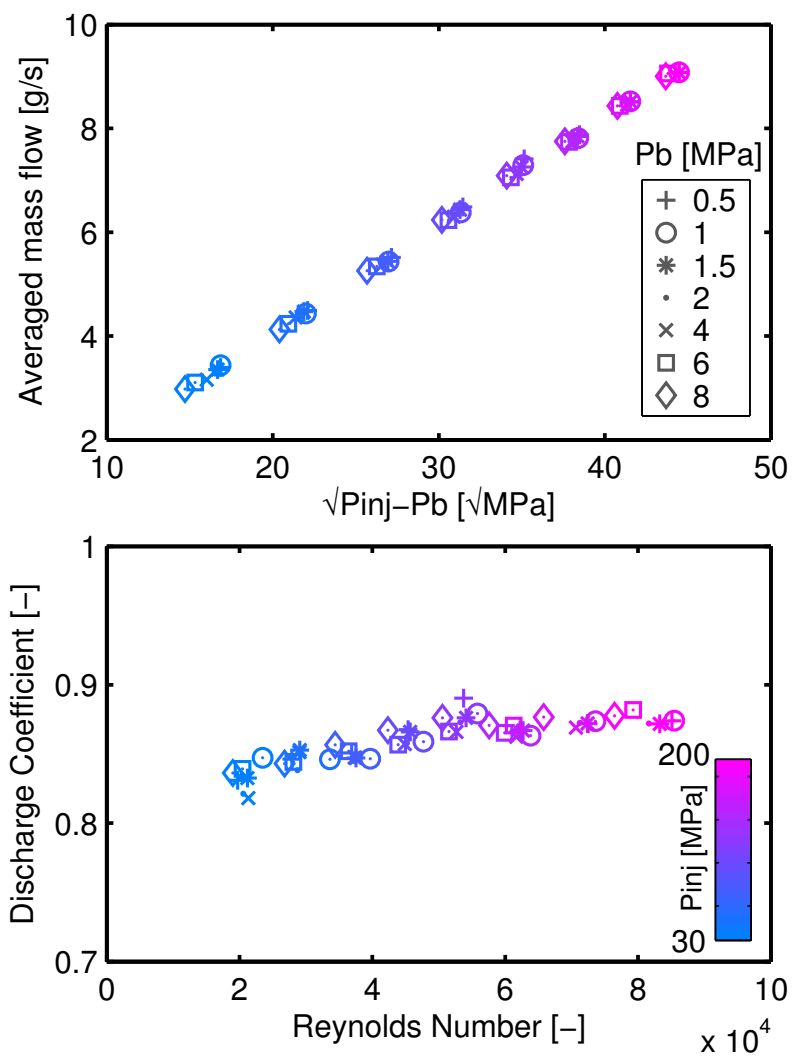

Figure 8: Hydraulic characterization results for Spray B nozzle. The top plot presents mass flow to the square root of the pressure difference. The bottom plot shows the discharge coefficient against the Reynolds number. Both plots show no apparent collapse of the mass flow. For a better color interpretation of this figure, the reader is referred to the web version of this article.

A linear relationship can be observed between the averaged mass flow and the square root of the pressure difference. Trends observed from both cases suggest that injector is not supercavitating. For very high injection pressures (e.g. 175 or $200 \mathrm{MPa}$ ) mass flow started to choke for decreasing back pressures, also reflected in the discharge coefficient, where it started reaching a constant value of around 0.88 for injection 
Raúl Payri, Gabriela Bracho, Pedro Martí-Aldaraví, Alberto Viera; Near field visualization of diesel spray for different nozzle inclination angles in non-vaporizing conditions. Atomization and Sprays, 2017, 27(3), 251-267.

pressures of $200 \mathrm{MPa}$. But still these conditions were not studied in the optical vessel, and no clear trend of choking in the mass flow, as seen in the literature (Nurick, 1976; Desantes et al., 2010, Payri et al., 2004a, 2008b), was observed. Additionally, nozzle nominal conicity factor ( $k$-factor 1.5) and inlet radius of $30 \mu \mathrm{m}$ suggest no supercavitation should appear in the nozzle, but still the formation of incipient cavitation cannot be discarded with such data. From the results, it is possible to conclude that fluctuations in the spray axis not sufficient to state that there is no incipient cavitation in the nozzle.

\subsection{Liquid jet breakup mechanism}

Using all ROI results, the Ohnesorge number was calculated with Equation 2, Figure 9 presents the Ohnesorge diagram with the limits proposed by Reitz and Bracco (1984). Note that the Reynolds number for this plot is presented in a logarithmic scale. The figure points out that all conditions tested, over the extended rate of injection matrix, result in a full atomization liquid jet breakup mechanism. With the clear trend observed, it is possible to conclude that spray axis angle fluctuations are not caused by non-uniform liquid wave breakup. This is also in agreement with results from Figure 7 because fluctuations increased with higher injection pressure, that results in better atomization conditions. Additionally, both nozzles should experiment similar liquid jet breakup, so the differences in spray angle axis fluctuations between nozzles cannot be related to the breakup mechanism.

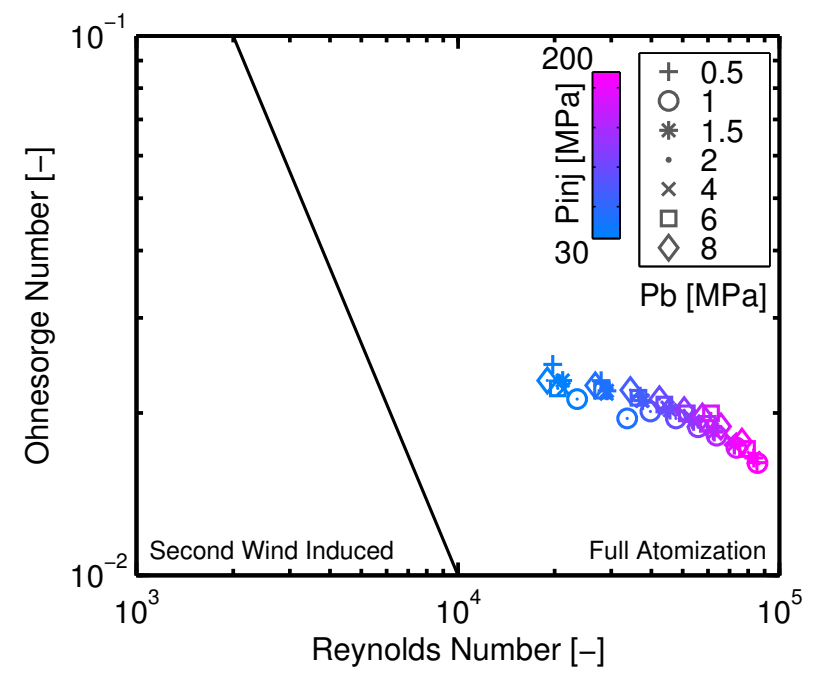

Figure 9: Ohnesorge number versus Reynolds number. The black solid line represents the frontier between second wind induced and full atomization liquid jet breakup mechanisms. For a better color interpretation of this figure, the reader is referred to the web version of this article. 
Raúl Payri, Gabriela Bracho, Pedro Martí-Aldaraví, Alberto Viera; Near field visualization of diesel spray for different nozzle inclination angles in non-vaporizing conditions. Atomization and Sprays, 2017, 27(3), 251-267.

\subsection{Spreading angle fluctuations}

Although rate of injection results show no choking in the averaged mass flow, still incipient cavitation can develop in the nozzle (Desantes et al., 2010). Consequently, the presence of vaporized fuel at the exit of the nozzle increases turbulence, that could lead to higher spray axis angle fluctuations. Both Payri et al. (2015) and Desantes et al. (2010), observed that cavitation induces spreading angle oscillations on the spray. Figure 10 presents spreading angle measurements for three random repetitions for both nozzles. Note that each repetition is presented as a color gradient, but the importance of this result is the clear difference in spreading angle fluctuations between Spray A and B nozzles, and that this behavior was observed throughout all test conditions.

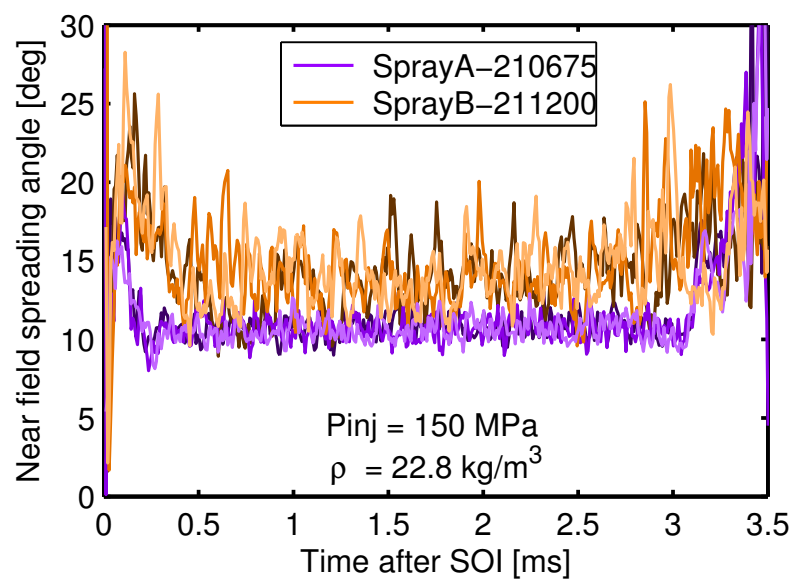

Figure 10: Spreading angle results per repetition. Color gradients represent random repetitions for the Spray A (purple) and Spray B (orange) for an injection event. The difference in fluctuations suggests the presence of relevant radial velocity components, or even incipient cavitation, in the Spray B nozzle.

In order to present these fluctuations as a numerical value, the same approach of Equation 4 was followed. Calculated spreading angle fluctuations $(\bar{\theta})$ are presented in Figure 11. Results are not only in agreement with spray axis angle fluctuations $(\bar{\alpha})$ in terms of the difference between both nozzles, but also suggest that relevant radial velocity components (due to high turbulence levels), or even incipient cavitation, are developing in Spray B nozzle and could originate these fluctuations. Additionally, as concluded from Figure 8, air entrainment effects appeared closer to the nozzle in Spray B, also indicating conditions of higher turbulence at the nozzle exit compared to Spray A. Furthermore, CFD modeling of the internal flow in Spray B nozzle, briefly presented in the ECN 3rd Workshop (ECN, 2010), showed the possibility of vapor bubbles or even cavitation forming towards nozzle exit. However, further CFD analysis is needed to understand complex phenomena happening in the nozzle internal flow development. 
Raúl Payri, Gabriela Bracho, Pedro Martí-Aldaraví, Alberto Viera; Near field visualization of diesel spray for different nozzle inclination angles in non-vaporizing conditions. Atomization and Sprays, 2017, 27(3), 251-267.

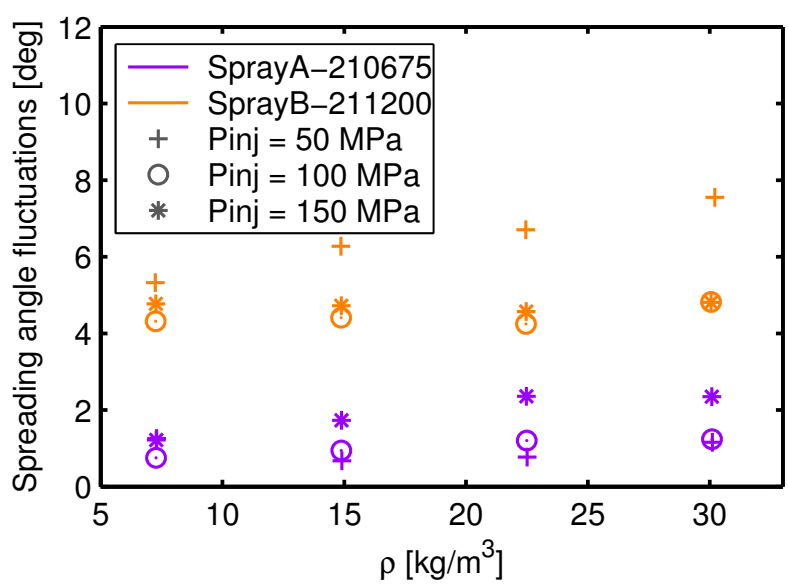

Figure 11: Spreading angle fluctuations results compared to density for Spray A (purple) and Spray B (orange), following the methodology proposed in Equation 4 Symbols present different injection pressure levels.

\subsection{Nozzle tip temperature effect on fluctuations}

Using a special injector holder that has a continuous flow of ethylene glycol which runs through a temperature controlled circuit, it is possible to regulate the injectors nozzle tip temperature for each injection event (Bardi et al. 2012). To observe the possible effect of fuel viscosity in spray axis angle fluctuations, additional tests were performed for Spray B nozzle varying the temperature of the ethylene glycol at three different levels: 303K, 323K, and 353K. Fuel viscosity was calculated using the open source thermophysical property library Coolprop, presented by Bell et al. (2014), and by approximating the fuel temperature to the parallel circuit set point. The study was performed with two gas densities of 15.2 and $22.8 \mathrm{~kg} / \mathrm{m}^{3}$ and the three injection pressures previously used. Using the same image processing and data averaging methodology, results obtained are presented in Figure 12. Although for lower viscosity a slight increase in the spray axis angle fluctuation is noted, no clear effect over the fluctuations is observed for the data gathered.

\section{Conclusions}

In this research, near field visualization of an axially drilled single orifice and a multi orifice injector, with nominally identical specifications, was performed at ambient temperature. The maximum field of view was $6 \mathrm{~mm}$ from nozzle tip, with 73 pixel-mm and a recording speed of $120 \mathrm{kfps}$. Liquid phase penetration was visualized with a diffused-back illumination technique, using a pulsed LED as light source, with a pulse length of $125 \mathrm{~ns}$. Spray tip penetration, spreading angle and spray axis angle fluctuations were measured and reported. A parametric sweep of three different injection pressures and four chamber densities was performed, to observe its impact on the studied macroscopic spray variables. Additionally, rate of injection 
Raúl Payri, Gabriela Bracho, Pedro Martí-Aldaraví, Alberto Viera; Near field visualization of diesel spray for different nozzle inclination angles in non-vaporizing conditions. Atomization and Sprays, 2017, 27(3), 251-267.

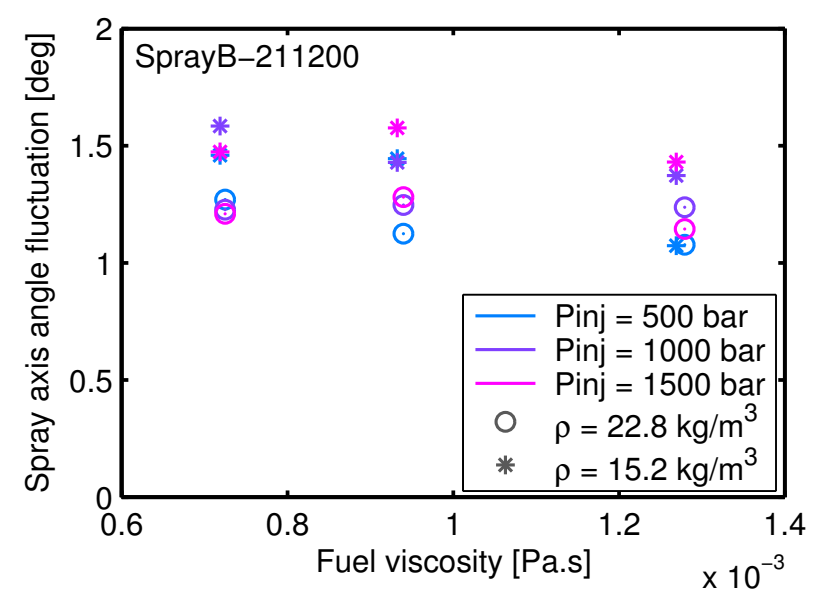

Figure 12: Effect of fuel viscosity in the spray axis angle fluctuations $(\bar{\alpha})$. For a better color interpretation of this figure, the reader is referred to the web version of this article.

measurements with a very detailed sweep in injection and back pressures was performed, to examine the hydraulic behavior of the Spray B nozzle and its relationship with spray axis angle fluctuations. The following conclusions can be drawn:

- Spray B nozzle showed slower spray tip penetration than Spray A, this could be due to lower sac pressure due to throttling at the needle seat. Additionally, near the nozzle, exchange of momentum between flow and ambient gas showed a stronger influence in spray tip penetration than air entrainment effects, as variations in injection pressures (thus flow velocity) had a bigger impact on penetration than changes in density, for the data range tested.

- Near field spreading angle followed the expected trend for Spray B, increasing with higher chamber density and injection pressure. On the contrary, density did not play a role in near field spreading angle for Spray A, proving that when flow exits the nozzle in an orderly fashion, air entrainment effects appear later in the spray development, and that turbulence improves fuel-air mixing.

- Spray axis angle fluctuations were observed for Spray B nozzle, on the contrary to Spray A, that showed negligible fluctuations. In general, higher fluctuations were observed when increasing injection pressure. Although chamber density played a minor role, a small decrease in spray axis angle fluctuations was reported at high injection pressures and decreasing density. These observations are useful for LES model validation.

- Rate of injection measurements showed that mass flow does not collapse for the test points studied in the optical vessel. Mass flow started to choke at very high injection pressures and low back pressures, 
Raúl Payri, Gabriela Bracho, Pedro Martí-Aldaraví, Alberto Viera; Near field visualization of diesel spray for different nozzle inclination angles in non-vaporizing conditions. Atomization and Sprays, 2017, 27(3), 251-267.

but no clear trend was observed. Therefore, supercavitation was discarded as a reason for the spray

Battistoni, M., Xue, Q., and Som, S. (2016). Large-Eddy Simulation ( LES ) of Spray Transients : Start and End of Injection Phenomena. Oil and Gas Science and Technology - Revue d'IFP Energies nouvelles, 71(1):24.

Bell, I. H., Wronski, J., Quoilin, S., and Lemort, V. (2014). Pure and pseudo-pure fluid thermophysical property evaluation and the open-source thermophysical property library coolprop. Industrial and Engineering Chemistry Research, 53(6):2498-2508. 01-2010.

Desantes, J. M., Payri, R., Salvador, F. J., and De la Morena, J. (2010). Influence of cavitation phenomenon on primary break-up and spray behavior at stationary conditions. Fuel, 89(10):3033-3041. 
Raúl Payri, Gabriela Bracho, Pedro Martí-Aldaraví, Alberto Viera; Near field visualization of diesel spray for different nozzle inclination angles in non-vaporizing conditions. Atomization and Sprays, 2017, 27(3), 251-267.

ECN (2010). Engine Combustion Network. Online.

Hulkkonen, T., Sarjovaara, T., Kaario, O., and Larmi, M. (2015). Experimental Study of Conical Diesel Nozzle Orifice Geometry. Atomization and Sprays, 25(6):519-538.

Jung, Y., Manin, J., Skeen, S., and Pickett, L. M. (2015). Measurement of Liquid and Vapor Penetration of Diesel Sprays with a Variation in Spreading Angle. SAE Technical Paper 2015-01-0946.

Kastengren, A. L., Tilocco, F. Z., Powell, C. F., Manin, J., Pickett, L. M., Payri, R., and Bazyn, T. (2012). Engine Combustion Network (ECN): Measurements of Nozzle Geometry and Hydraulic Behavior. Atomization and Sprays, 22(12):1011-1052.

Manin, J., Bardi, M., and Pickett, L. M. (2012). Evaluation of the liquid length via diffused back-illumination imaging in vaporizing diesel sprays. In Comodia, volume 2012, pages 665-673, Fukuoka.

Manin, J., Bardi, M., Pickett, L. M., and Payri, R. (2016). Boundary condition and fuel composition effects on injection processes of diesel sprays at the microscopic level. International Journal of Multiphase Flow, 83:267-278.

Mendez, Y. N., Bardi, M., Viera, J. P., and Payri, R. (2013). An Experimental Approach in the Impact of Electric Fields on Liquid Fuel Spray Injection. SAE Technical Paper 2013-01-160\%.

Mishra, C. and Peles, Y. (2005). Cavitation in flow through a micro-orifice inside a silicon microchannel. Physics of Fluids, 17(1):13601.

Nurick, W. H. (1976). Orifice cavitation and its effects on spray mixing. Journal of fluids engineering, 98:681-687.

Pastor, J. V., Lopez, J. J., Garcia-Oliver, J. M., and Pastor, J. M. (2008). A 1D model for the description of mixing-controlled inert diesel sprays. Fuel, 87(13-14):2871-2885.

Payri, F., Bermúdez, V., Payri, R., and Salvador, F. J. (2004a). The influence of cavitation on the internal flow and the spray characteristics in diesel injection nozzles. Fuel, 83(4-5):419-431.

Payri, R., Garcia-Oliver, J. M., Bardi, M., and Manin, J. (2012). Fuel temperature influence on diesel sprays in inert and reacting conditions. Applied Thermal Engineering, 35:185-195.

Payri, R., Garcia-Oliver, J. M., Salvador, F. J., and Gimeno, J. (2005). Using spray momentum flux measurements to understand the influence of diesel nozzle geometry on spray characteristics. Fuel, 84(5):551-561.

Payri, R., Gimeno, J., Bracho, G., and Vaquerizo, D. (2016a). Study of liquid and vapor phase behavior on Diesel sprays for heavy duty engine nozzles. Applied Thermal Engineering, 107:365-378.

Payri, R., Gimeno, J., Viera, J. P., and Plazas, A. H. (2013). Needle lift profile influence on the vapor phase penetration for a prototype diesel direct acting piezoelectric injector. Fuel, 113:257-265.

Payri, R., Molina, S., Salvador, F. J., and Gimeno, J. (2004b). A study of the relation between nozzle geometry, internal flow and sprays characteristics in diesel fuel injection systems. KSME International Journal, 18(7):1222-1235.

Payri, R., Salvador, F. J., Gimeno, J., and Bracho, G. (2008a). A new methodology for correcting the signal cumulative phenomenon on injection rate measurements. Experimental Techniques, 32(1):46-49.

Payri, R., Salvador, F. J., Gimeno, J., and Viera, J. P. (2015). Experimental analysis on the influence of nozzle geometry over the dispersion of liquid n-dodecane sprays. Frontiers in Mechanical Engineering, 1:1-13.

Payri, R., Salvador, F. J., Gimeno, J., and Zapata, L. D. (2008b). Diesel nozzle geometry influence on spray liquid-phase fuel penetration in evaporative conditions. Fuel, 87(7):1165-1176.

Payri, R., Salvador, F. J., Manin, J., and Viera, A. (2016b). Diesel ignition delay and lift-off length through different methodologies using a multi-hole injector. Applied Energy, 162:541-550.

Pierpont, D. A. and Reitz, R. D. (1995). Effects of injection pressure and nozzle geometry on D.I. Diesel emissions and 
Raúl Payri, Gabriela Bracho, Pedro Martí-Aldaraví, Alberto Viera; Near field visualization of diesel spray for different nozzle inclination angles in non-vaporizing conditions. Atomization and Sprays, 2017, 27(3), 251-267.

performance. SAE Paper 950604.

Reitz, R. D. and Bracco, F. V. (1984). Mechanism of breakup of round liquid jets. In Cheremisnoff, N., editor, Encyclopedia of Fluids Mechanics, volume 3, chapter 10, pages 233-249. Gulf Publishing, Houston.

Siebers, D. L. (1998). Liquid-phase fuel penetration in diesel sprays. SAE Technical Paper 980809.

Siebers, D. L. and Higgins, B. (2001). Flame Lift-Off on Direct-Injection Diesel Sprays Under Quiescent Conditions. SAE Technical Paper 2001-01-0530.

Sou, A. and Pratama, R. H. (2016). Effects of Asymmetric Inflow on Cavitation in Fuel Injector and Discharged Liquid Jet. Atomization and Sprays, 26(9):939-959.

Winklhofer, E., Kull, E., Kelz, E., and Morozov, A. (2001). Comprehensive hydraulic and flow field documentation in model throttle experiments under cavitation conditions. In ILASS-Europe, Zurich. 